\title{
準剛体回転流による高精度湿式遠心分級
}

\author{
—バッチ方式の分級原理と性能-
}

\section{Accurate Wet-type Centrifugal Classification Using an Almost Rigidly Rotating Flow - Classification Principle and Performance of the Batch-type Classificaiton -}

\author{
中 林 功 - * 土 田陽 - * \\ Koichi NAKABAYASHI, Yoichi TSUCHIDA
}

\begin{abstract}
We have proposed a new system for an accurate wet-type centrifugal classification to which an almost rigidly rotating through-flow is applied. This flow can be produced within a highly rotating double-walled container, without any turbulent fluctuation. In the present paper, we have employed the batch-type classification with a cylinder-sphere-shaped container in classification experiments, theoretical and numerical flow analyses and flow-visualization measurements. Consequently, we have obtained the following main conclusions; (1) with decreasing Ekman number (i. e. increasing rotation rate) at a constant Rossby number or with decreasing Rossby number (decreasing through-flow rate) at a constant Ekman number, the cut size and fine yield decrease and the classification accuracy increases, (2) for the occurrence of rigid - rotation region which is indispensable to collect the coarse product, it is necessary to make the flow field inverse- $\mathrm{C}$-shaped towards the rotation axis.
\end{abstract}

Key Words : Wet-type Centrifugal Classification, Almost Rigid Rotation, Partial Fractional Efficiency, Ekman Layer, Stewartson Layer

\section{1. 緒言}

半導体産業をはじめとする先端技術分野を支える IC 基板, 膜材料, ファインセラミックスなどの新素 材では，その材料特性を高度化・高機能化するため に, 原料粉体の粒度調整が重要となっている。近年, ユーザー・ニーズの高度化と多様化に伴って, 粒度の 均一化とサブミクロン化の要求がますます厳しくなっ ており，今後なお一層その傾向が強まる方向にある。

粉体の製造プロセスは, ブレイキングダウン・プロ セス（溶湯噴霧, 機械的粉砕など）とビルディングア ップ・プロセス（化学的合成）の二つに大別できる が，両プロセスともに程度の差こそあれ製造した粉体 に粒度分布が生じることは避けることができない。し たがって，上述の先端技術関連では製品化の最後の工 程として精密微粉分級が必要である。

1999年 6 月 15 日受付

粉体工学会1998年度秋期研究発表会 (1998年11月，東京) にて発表 *名古屋工業大学機械工学科

（广466-8555 名古屋市昭和区御器所町）TEL 052-735-5323 Department of Mechanical Engineering.

Nagoya Institute of Technology

(Gokiso-cho, Showa-ku, Nagoya 466-8555)
このような背景のもとに種々の乾式および湿式分級 機が開発されてきた ${ }^{123}$ が，粒度調整に対する上述の 要求を十分に満たす精密微粉分級が実現しているとは いいがたい。これを達成するためには，持続的に働く 強力な分離力, 乱れのない流れ (層流), 良好な粒子 分散, 分級産物（粗粉産物之微粉産物）の混合阻止の 4 条件を兼敉備えることが必要である4)。しかし，従 来の遠心分級方式では, 強力な分離力を発生する高速 回転において，乱れのない流れ条件を完全に満足する ことは原理的に不可能である。

そこで著者らは，いくら高速回転にしても原理的に 乱れの発生しない準剛体回転成層流（安定な層流）の 中で分級を行う新しい湿式遠心分級方式を提案する。 この分級方式は，バッチ方式はもとより連続方式への 拡張が可能である。Fig. 1 は, バッチ方式の分級場の 流れ構造と粒子軌道を示す。その詳細は後述するが, 上記の準剛体回転流は高速回転する軸対称の二重容器 （ハウジングとコア）内に微量の液体（水）を流すこ とによって生成され，この完全軸対称な層流の流れ場 に原料粉体分散液を流すことにより精密微粉分級が可 能となる。なお本分級方式では, 分散液の質量濃度が 希薄な場合（およそ数\%以下）を対象としている。 


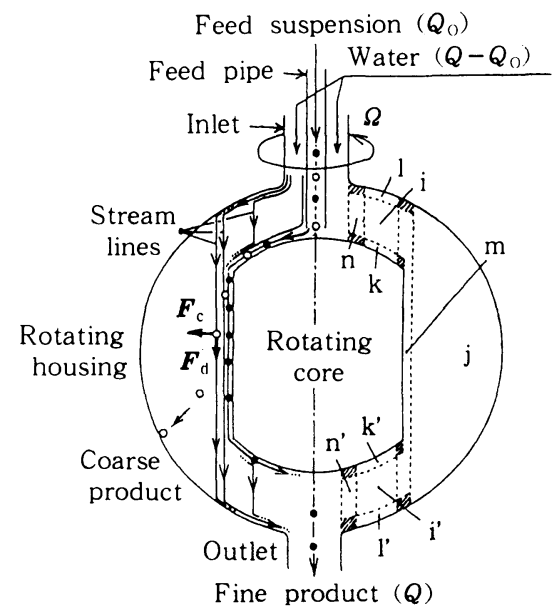

Fig. 1 Schematic of the almost rigidly rotating flow structure and particle path within a rotating double-walled container for the batch-type classification ( $\mathrm{k}, \mathrm{l}, \mathrm{k}, \mathrm{l}$ ' : Ekman layers ; $m, n, n^{\prime}:$ Stewartson layers ; $\mathrm{i}, \mathrm{i}$ : : interior regions ; $\mathrm{j}$ : rigid-rotation region; hatching : Ekman extensions of Stewartson layers; $\bigcirc$ : coarse particles; - : fine particles; $\boldsymbol{F}_{\mathrm{c}}, \boldsymbol{F}_{\mathrm{d}}$ : centrifugal and drag forces)

本分級方式は，従来の方式（乱れを伴う流れ場）に 比べて分級精度の面で压倒的に有利である。なぜな ら，本方式の分級限界が原理的にブラウン拡散によっ て決まるのに対し, 後者は乱流拡散の影響を受けるか らである。例えば 1 気圧, $20^{\circ} \mathrm{C}$ (絶対温度 $T=293 \mathrm{~K}$ ) の水中（粘度 $\mu=1.002 \times 10^{-3} \mathrm{~Pa} \cdot \mathrm{s}$ ，カニンガムの補 正係数 $\left.C_{\mathrm{c}}=1\right)$ における直径 $D_{\mathrm{P}}=0.1 \mu \mathrm{m}$ の球形粒子 のブラウン拡散係数 $\kappa T C_{\mathrm{c}} /\left(3 \pi \mu D_{\mathrm{P}}\right)$ は $4.28 \times 10^{-12}$ $\mathrm{m}^{2} / \mathrm{s}$ （ボルツマン定数 $\kappa=1.38 \times 10^{-23} \mathrm{~J} / \mathrm{K}$ ）である か，乱流拡散係数は例えば湿式の水平流型重力分級機 の場合 $10^{-6} \mathrm{~m}^{2} / \mathrm{s}$ の程度であり, ブラウン拡散係数の 值は乱流拡散係数に比へ格段に小さい。

本方式は上述の特色をもつのみでなく，持続的に働 く強力な分離力之分級産物の混合阻止の特色も兼敉備 えている。すなわち後述のように，まずエクマン層で の強いせん断流れにより粒子間距離が広がり, 次のス チュワートソン層での高速回転流れによりさらにその 距離が広がって分級が達成され, 分級後の粗粉産物は 剛体回転領域へ閉じ込められて微粉産物へ混入するこ とはない。

一方, ウラン濃縮のためのガス遠心分離に関する研 究5)では, 回転円筒容器内に生成させたスチュワート ソン層のみを主に活用し, 本研究のようにエクマン
層, スチュワートソン層, 剛体回転領域のすべてを積 極的に活用する分離方式は未だ研究されていない。

本論文では，バッチ方式について，分級の原理と特 徵, 分級試験による性能評価, ならびに分級に応用し ている準剛体回転流について述べる。

\section{2. 分級の原理}

Fig. 1 は, 回転二重容器内の安定な軸対称の準剛体 回転流の構造および粒子軌道を示す。 $\Omega$ は回転容器の 角速度, $Q$ は貫流量（原料粉体分散液の流量 $Q_{0}$ 之水 の流量 $Q-Q_{0}$ の合計）である。この準剛体回転流 は, 後に詳述するようにエクマン層 $\mathrm{k}, \mathrm{l}, \mathrm{k}, \mathrm{l}$, スチ ュワートソン層 $\mathrm{m}, \mathrm{n}, \mathrm{n}^{\prime}$, 内部領域 $\mathrm{i}, \mathrm{i}^{\prime}$ および剛体 回転領域 $\mathrm{j}$ からなる。な捕線部はスチュワートソン 層とエクマン層が重なった部分（スチュワートソン層 のエクマン・エクステンション) である。原料粉体分 散液は, フィードパイプによりコアの回転軸上に供給 され，そこからnの下部のエクマン・エクステンショ ンを経て $\mathrm{k}$ (コア壁面側) へ進む。他方, 流入口から 供給される水は $\mathrm{n}$ を経て $\mathrm{k}$ （内部領域 $\mathrm{i}$ 側）または 1 へ進む。粉体粒子は $\mathrm{k}$ と然において, 粒径に応じた遠 心力 $\boldsymbol{F}_{\mathrm{c}}$ と流体抗力 $\boldsymbol{F}_{\mathrm{d}}$ による分級作用を受ける。そ の結果, 微粒子（の）はmから k' またはl'に進み, 流出口から微粉産物として捕集される。一方, 粗粒子 （○）はmから剛体回転領域 $\mathrm{j} に 入 り ， \mathrm{j} に$ に接した八 ウジング壁面に付着する。付着した粗粒子は, 分級終 了後に流出口から粗粉産物として捕集される。なお $\mathrm{j}$ にいったん入り込んだ粗粒子は流れ構造上ここから出 ることが不可能で, 粗粒子が微粉産物へ混入すること は起こり得ない。

微小な球形粒子に働く遠心力 $\boldsymbol{F}_{\mathrm{c}}$ および流体抗力 （ストークス抵抗） $\boldsymbol{F}_{\mathrm{d}}$ は，次式で与えられる。

$$
\begin{aligned}
& \boldsymbol{F}_{\mathrm{c}}=\left(\rho_{\mathrm{P}}-\rho_{\mathrm{f}}\right)\left(\pi D_{\mathrm{P}}^{3} / 6\right) \Omega^{2} r^{*} \boldsymbol{i} \\
& \boldsymbol{F}_{\mathrm{d}}=3 \pi \mu D_{\mathrm{P}}\left(\boldsymbol{v}^{*}-\boldsymbol{u}^{*}\right) \\
& \therefore \quad\left|\boldsymbol{F}_{\mathrm{c}}\right| /\left|\boldsymbol{F}_{\mathrm{d}}\right|=(\gamma-1)\left(D_{\mathrm{P}} / a\right)^{2} r /\left(18 E R_{\mathrm{S}}|\boldsymbol{v}-\boldsymbol{u}|\right)
\end{aligned}
$$

ここで，上付き添字*がとれた変数 $(\boldsymbol{r}, \boldsymbol{v}, \boldsymbol{u})$ は, 代表 長さ $a$ あるいは代表速度 $U_{\mathrm{E}}$ による無次元量である。 本研究では, $a$ をコアの円柱面の半径, $U_{\mathrm{E}}$ を厚さが $\mathrm{O}\left((\nu / \Omega)^{0.5}\right)$ のエクマン層内の平均半径速度の目安で ある $Q /\left\{4 \pi a(\nu / \Omega)^{0.5}\right\}$ とする。 $E, R_{\mathrm{S}}$ は次式で定義さ れる流れの支配パラメータで, それぞれエクマン数 (流体に作用するコリオリ力に対する粘性力の比), 口 スビー数（コリオリカに対する慣性力の比）である。 


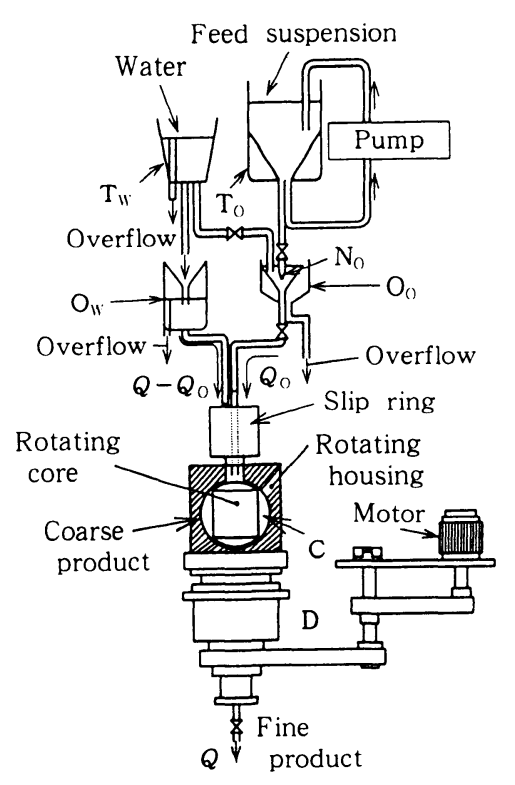

(a) Total system ( $\mathrm{C}$ : rotating container; $D$ : driving system, $T_{()}, T_{W}$ : tanks for the feed suspension and water ; $\mathrm{O}_{(1}, \mathrm{O}_{W}$ : overflow tanks for the feed suspension and water $\mathrm{N}_{()}$: dispersion nozzle)

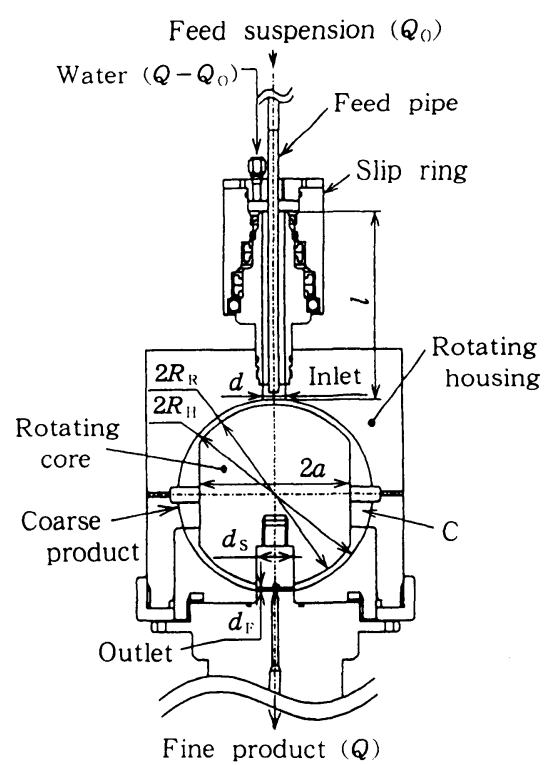

(b) Rotating container $\mathrm{C}$ and slip ring (dimensions (units $\mathrm{mm}$ ) : housing : $R_{11}=94.49$; core : $a=72.64, R_{\mathrm{R}}=87.90$; inlet : $d=\phi 21.8, l=179.5$; outlet : $d_{\vDash}=4-\phi 4, d_{\mathrm{S}}=\phi 34$ )

Fig. 2 Experimental apparatus

$\gamma$ は流体密度に対する粒子密度の比 $\left(\gamma=\rho_{\mathrm{P}} / \rho_{\mathrm{f}}\right)$ であ る。

$$
\begin{aligned}
& E=\nu /\left(\Omega a^{2}\right) \sim 1 / n, \\
& R_{\mathrm{S}}=U_{\mathrm{E}} /(\Omega a) \sim Q / n^{0.5} \quad(n=30 \Omega / \pi)
\end{aligned}
$$

前述の準剛体回転流は, 後述するように微小な $E$ および $R_{\mathrm{S}}$ の条件下で生成される。すなわち，微小な 貫流量 $Q$ のもとではいくら回転数 $n$ を高速にしても 流れに乱れがまったく発生しないので, 層流状態を保 ったまま回転数を自由に増減でき, Eq. (3) の遠心力 と流体抗力の比を任意に設定できる。ゆえに $E$ を減 少（ $n$ を増大）または $R_{\mathrm{S}}$ を減少（ $Q / n^{0.5}$ を減少）さ せてこの比を増大させることにより，高精密なサブミ クロン分級が可能となる。

\section{3. 分級試験による性能評価}

\section{1 実験装置および方法}

Fig. 2 （a）は分級実験装置を示す。これは，回転容 器 $\mathrm{C}$, 駆動系 $\mathrm{D}$, スリップリング, 原料粉体分散液用 タンク $\mathrm{T}_{\mathrm{O}}$, 給水用タンク $\mathrm{T}_{\mathrm{W}}$, ならびにそれぞれ原料 粉体分散液, 水を一定流量で供給するオーバーフロー タンク $\mathrm{O}_{\mathrm{O}}, \mathrm{O}_{\mathrm{w}}$ よりなる。なお, ポンプとノズル $\mathrm{N}_{\mathrm{O}}$
は実験中の分散液の凝集防止のために用いた。

Fig. 2 (b) はC とスリップリングの詳細を示す。八 ウジング（透明なアクリル樹脂製）の内面は球面（半 径 $94.49 \mathrm{~mm}$ ) で, コア (ジュラルミン製) の外面は 球面 (半径 $87.90 \mathrm{~mm}$ ) と円柱面 $(a=72.64 \mathrm{~mm}$ ) か らなる。フィードパイプは, スリップリングの静止系 に固定されている。

原料粉体分散液は, 原料粉体, 分散媒および分散剂 よりなる。原料粉体は真比重 $\gamma$ が 1.19 のポリメタク リル酸メチルの球形粒子（積水化成品工業, テクポリ マ-MB-4), 分散媒は水, 分散剂は液体の合成洗剂 （日本生活協同組合連合会, Kソフト) である。本実 験では, 原料粉体分散液に対する原料粉体の質量濃度 $C_{\mathrm{O}}$ を $0.5 \%$ ，分散剂の質量濃度を $0.6 \%$ とした。

分級試験方法は以下のとおりである ${ }^{6)}$ 。まず原料粉 体分散液の代わりに水を供給して, 回転容器の回転数 $n$, 貫流量 $Q$, 原料粉体分散液の流量 $Q_{\mathrm{O}}$ を設定す る。すなわちエクマン数 $E$, ロスビー数 $R_{\mathrm{S}}$, 原料粉 体分散液の流量比 $k_{O}\left(=Q_{O} / Q\right)$ を設定する。次に水を 原料粉体分散液に切り換えることにより分級試験を開 始し, 再び水に戻すことによって終了する。なお本実 験装置（代表長さ $a=0.07264 \mathrm{~m}$ ) では, $20^{\circ} \mathrm{C}$ の水の 
場合, $E, R_{\mathrm{S}}$ と $n(\mathrm{rpm}), Q\left(\mathrm{~m}^{3} / \mathrm{s}\right)$ との間に次の関係 がある。

$$
\begin{array}{ll}
E=1.82 \times 10^{-3} / n, & R_{\mathrm{S}}=4.65 \times 10^{4} Q / n^{0.5} \\
n=1.82 \times 10^{-3} / E, & Q=9.16 \times 10^{-7} R_{\mathrm{S}} / E^{0.5}
\end{array}
$$

本実験では流量比 $k_{\mathrm{O}}$ を 0.15 の一定値に設定したが, この場合の原料粉体分散液の流量 $Q_{\mathrm{O}}$ は, 原料粉体分 散液が供給されるエクマン層 $\mathrm{k}$ を通過する流量（後述 のエクマン輸送量 $q$ ) の理論值の約 $30 \%$ に相当す る。

粒度測定は, 光透過式の遠心沈降式粒度分布測定装 置（島津製作所, SA-CP4L) により行い, ふるい上 積算分布（質量基準） $R\left(D_{\mathrm{P}}\right)$ を求めた。

$$
\begin{aligned}
\eta_{\mathrm{F}} & =\text { 微粉産物の質量流量/原料粉体の質量流量 } \\
& =\rho_{\mathrm{f}} Q C_{\mathrm{F}} /\left(\rho_{\mathrm{f}} Q_{\mathrm{O}} C_{\mathrm{O}}\right)=C_{\mathrm{F}} /\left(k_{\mathrm{O}} C_{\mathrm{O}}\right)
\end{aligned}
$$

で定義される微粉収率 $\eta_{\mathrm{F}}$ は， $k_{\mathrm{O}} ， C_{\mathrm{O}}$ が上述のように 設定值であるので, 微粉産物の質量濃度 $C_{\mathrm{F}}$ を測定す ることにより求められる。 $C_{\mathrm{F}}$ は, 微粉産物を滤紙で 濾過後, $-300 \mathrm{mmHg}$, 約 $60^{\circ} \mathrm{C}$ で減圧乾燥させて求 めた（常压下での高温乾燥では粉体が変質するた め)。

\section{2 分級性能の評価方法}

本研究では, 分級性能をより正確に評価するため, 粒度測定によって得られる原料粉体, 微粉産物のふる い上積算分布 $R_{\mathrm{O}}\left(D_{\mathrm{P}}\right), R_{\mathrm{F}}\left(D_{\mathrm{P}}\right)$ の離散デー夕を, 次式 のように関数近似した（添字 $\mathrm{O}, \mathrm{F}$ は省略)。

$$
\begin{gathered}
R=10 \exp (-10 \exp y) \\
\quad\left(\text { i.e., } y=\log _{10}\left\{\log _{10}(1 / R)\right\}\right), \\
y=A_{1} x+A_{2} \sin \left(A_{3} x\right)+A_{4}, x=\log _{10} D_{\mathrm{P}}
\end{gathered}
$$

ただし $A$ は定数で, 最小 2 乗近似法により求めた。 この関数近似は，Fig. 3 に示すように，ロージン・ラ ムラ一線図 $\left(x-y\right.$ 平面) 上での直線近似 $y=A_{5} x+A_{6}$ (ロージン・ラムラー近似に対応) よりも近似精度がよ $<, R$ の近似誤差を粒度測定の繰返し測定の䛊差以下 （約 $5 \%$ 以下）に抑えることができた。

次式で定義される原料粉体，微粉産物の頻度分布 $f_{\mathrm{O}}, f_{\mathrm{F}}$ は, Eq. (8) から得られる微分係数 $\mathrm{d} R / \mathrm{d} D_{\mathrm{P}}$ お よびEq. (7) の微粉収率 $\eta_{\mathrm{F}}$ より求められる。

$$
f_{\mathrm{O}}\left(D_{\mathrm{P}}\right)=-\mathrm{d} R_{\mathrm{O}} / \mathrm{d} D_{\mathrm{P}}, f_{\mathrm{F}}\left(D_{\mathrm{P}}\right)=-\eta_{\mathrm{F}} \mathrm{d} R_{\mathrm{F}} / \mathrm{d} D_{\mathrm{P}}
$$

微粉産物の部分分級効率は, 次式により求められ る。

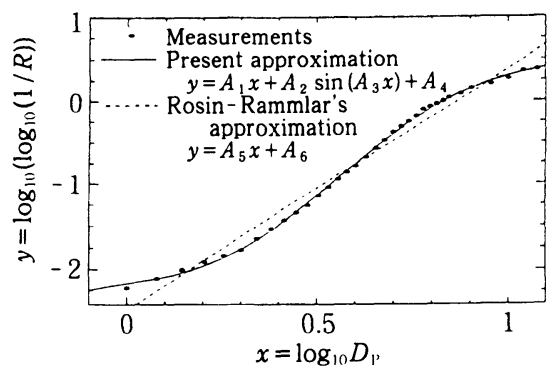

Fig. 3 Approximation of the mass-base oversize distribution $R\left(D_{1}\right)$ in the Rosin-Rammlar diagram of the $x-y$ plane $\left(D_{1},(\mu \mathrm{m}), R(-)\right)$

$$
\Delta \eta\left(D_{\mathrm{P}}\right)=f_{\mathrm{F}}\left(D_{\mathrm{P}}\right) / f_{\mathrm{O}}\left(D_{\mathrm{P}}\right)
$$

なお粗粉産物のふるい上積算分布と頻度分布は, 分 級前後の質量保存則から次式のように求められる。

$$
\begin{aligned}
& R_{\mathrm{C}}=\left(R_{\mathrm{O}}-\eta_{\mathrm{F}} R_{\mathrm{F}}\right) /\left(1-\eta_{\mathrm{F}}\right) \\
& f_{\mathrm{C}}\left(D_{\mathrm{P}}\right)=f_{\mathrm{O}}\left(D_{\mathrm{P}}\right)-f_{\mathrm{F}}\left(D_{\mathrm{P}}\right)
\end{aligned}
$$

\section{3 分級試験結果および考察}

Fig. 4 は, エクマン数 $E=7.0 \times 10^{-6}$, ロスビー数 $R_{\mathrm{S}}=8.3 \times 10^{-3}$ (Eq. (6) より $n=260 \mathrm{rpm}, Q=2.87 \times$ $10^{-6} \mathrm{~m}^{3} / \mathrm{s}$ ）の場合に得られる（a）ふるい上積算分 布 $R\left(D_{\mathrm{P}}\right)$ ，（b）頻度分布 $f\left(D_{\mathrm{P}}\right) ，$ （c）部分分級効率 $\Delta \eta\left(D_{\mathrm{P}}\right)$ を示す。ふるい上積算分布の各離散データ は, 前述の近似関数 (Eqs. (8), (11)) による曲線で ほぼ正確に近似されている。頻度分布から知られるよ うに分級径 $D_{\mathrm{P} 50}\left(f_{\mathrm{F}}=f_{\mathrm{C}}\right.$ となる粒径 $)$ は $4.40 \mu \mathrm{m}$ でミ クロンオーダであるが，これは回転数 $n$ が上記のよ うに低いためである。しかしながら, 部分分級効率か ら知られるように分級の鋭さ $S(\Delta \eta$ が $25 \%$ と $75 \%$ となる粒径の比 $D_{\mathrm{P} 25} / D_{\mathrm{P} 75}$ で完全分級の場合 $S=1$ ）は 1.49 であり, 低速回転にもかかわらず比較的高精度 值が得られる。

Fig. 5 は, ロスビー数が一定 $\left(R_{\mathrm{S}}=8.3 \times 10^{-3}\right.$, $\left.Q / n^{0.5}=1.78 \times 10^{-7} \mathrm{~m}^{3} / \mathrm{s}^{0.5}\right)$ の場合における部分分 級効率のエクマン数 $E$ (回転数 $n$ ) への依存性を示 す。部分分級効率は， $E$ の減少 ( $n$ の増大) に対して 大きな粒径においてかなり減少する一方で，小さな粒 径では少し増大し, 横軸に垂直な完全分級の効率曲線 に近づく。

Fig. 6 は, Fig. 5 から求めた分級の鋭さ $S$ および分 級径 $D_{\mathrm{P} 50}(\Delta \eta=50 \%$ となる粒径 $)$ のエクマン数 $E$ 一 の依存性を示す。 $D_{\mathrm{P} 50}$ は $E$ の減少（回転数 $n$ の増大） とともに小さくなる。これは，粒子に作用する流体抗 


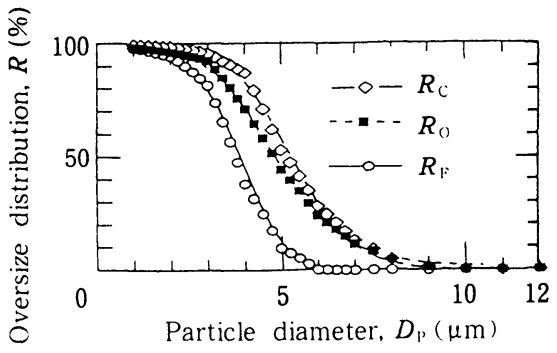

(a) Oversize distributions

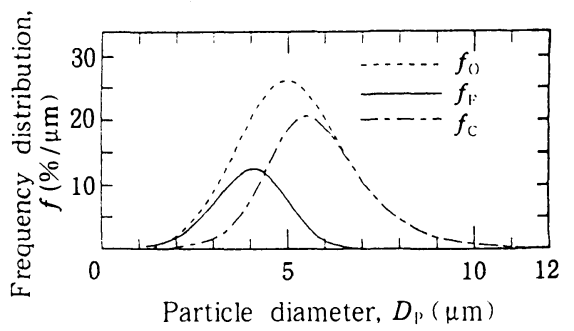

(b) Frequency distributions

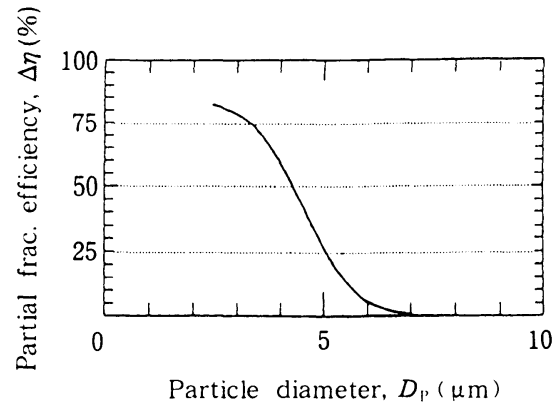

(c) Partial fractional efficiency of the fine product

Fig. 4 Classification performance for $E=7.0 \times 10^{-6}$ and $R_{\mathrm{S}}=8.3 \times 10^{-3}$

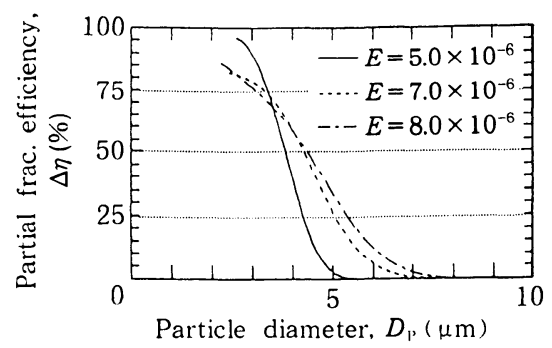

Fig. 5 Dependence of the partial fractional efficiency on the Ekman number $E$ for $R_{\mathrm{S}}=8.3 \times 10^{-3}$

力に対する遠心力の比 (Eq. (3)) が $E$ の減少に伴っ て増大するためである。他方, $S$ は $E$ の減少とともに 完全分級の值 $(S=1)$ に近づく。これは, 遠心力効果

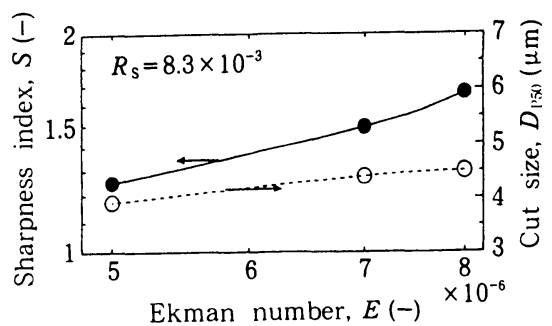

Fig. 6 Dependence of the sharpness index and the cut size on the Ekman number for $R_{\mathrm{S}}=8.3 \times 10^{-3}$

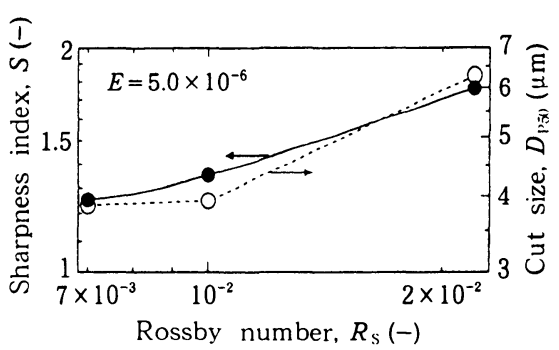

Fig. 7 Dependence of the sharpness index and the cut size on the Rossby number for $E=5.0 \times 10^{-6}$

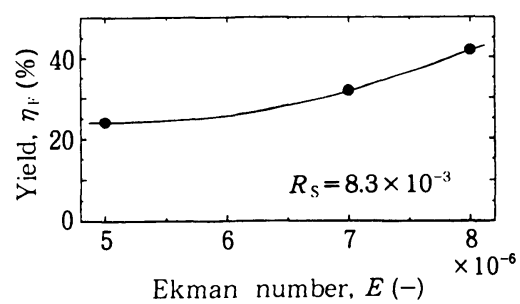

(a) Ekman number dependence for $R_{\mathrm{S}}=8.3 \times 10^{-3}$

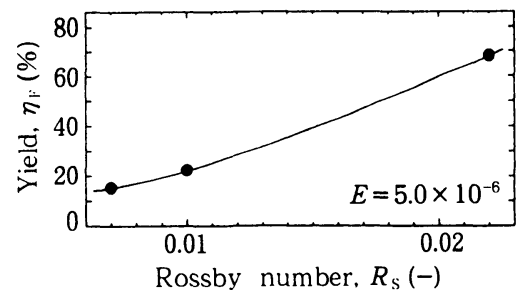

(b) Rossby number dependence for $E=5.0 \times 10^{-6}$

Fig. 8 Dependence of the yield of fine product on the Ekman and Rossby numbers

の増大が分級精度の向上をもたらすことを示してい る。

Fig. 7は, エクマン数が一定 $\left(E=5.0 \times 10^{-6}, n=\right.$ $363 \mathrm{rpm}$ ）の場合に得られる分級の鋭さ $S$ および分級 
径 $D_{\mathrm{P} 50}$ のロスビー数 $R_{\mathrm{S}}$ （貫流量 $Q$ ）への依存性を示 す。 $D_{\mathrm{P} 50}$ は $R_{\mathrm{S}}$ の減少 $(Q$ の減少) とともに小さくな る。これは，流体抗力に対する遠心力の比 (Eq. (3)) が $R_{\mathrm{S}}$ の減少に伴って増大するためである。つまり, 貫流量の減少による流体抗力の減少のため相対的に遠 心力効果が増大し，その結果分級径は小さくなる。他 方, $S$ は $R_{\mathrm{S}}$ の減少とともに 1 に近づく。この分級精 度の向上も, 上述の遠心力効果の増大による。

Fig. 8は, 微粉収率 $\eta_{\mathrm{F}}$ のエクマン数 $E$, ロスビー数 $R_{\mathrm{S}}$ への依存性を示す。 $\eta_{\mathrm{F}}$ は, $R_{\mathrm{S}}$ が一定 $\left(Q / n^{0.5}\right.$ が 一定）の場合 $E$ の減少（ $n$ の増大）とともに, そして $E$ が一定 $\left(n\right.$ が一定) の場合は $R_{\mathrm{S}}$ の減少 $(Q$ の減 少）とともに小さくなる。これは，上述のように流体 抗力に対する遠心力の比が $E$ あるいは $R_{\mathrm{S}}$ の減少に伴 って増大するため, より細かい粒子が粗粉産物とな り，その結果微粉産物の割合が減少するからである。

\section{4. 分級に応用している準剛体回転流の考察}

\section{1 準剛体回転流の概略}

原料粉体分散液の質量濃度が希薄な場合, 流れは媒 液 (非圧縮・粘性流体である水) の単相流として取り 扱うことができる。回転座標系におけるこの定常流れ （速度 $\boldsymbol{u}$, 遠心力を除いた圧力 $p$ ）の無次元支配方程式 （無次元化は前と同じ）は, 次式のナヴィエ・ストー クス式（各項の意味を明記）と連続式で与えられる。

$$
\begin{aligned}
& R_{\mathrm{S}}(\boldsymbol{u} \cdot \nabla) \boldsymbol{u}+2 \boldsymbol{k} \times \boldsymbol{u}=-\nabla p+E \nabla^{2} \boldsymbol{u} \\
& (\text { 慣性力) (コリオリ力) (压力勾配) (粘性力) } \\
& \nabla \cdot \boldsymbol{u}=0
\end{aligned}
$$

準剛体回転流 ${ }^{7.81}$ は, ロスビ一数 $R_{\mathrm{S}}$ が微小（微小 貫流量・高速回転）の場合の流れで, 次式で表され る。

$$
2 \boldsymbol{k} \times \boldsymbol{u}=-\nabla p+E \nabla^{2} \boldsymbol{u}
$$

壁近傍や流れのせん断の大きなところに生じるエクマ ン層, スチュワートソン層と呼ばれる境界層内では, 上式が支配方程式となる。境界層以外の内部領域と呼 ばれる領域では, 粘性力の影響が無視できるので, コ リオリ力と圧力勾配がつりあう地衡流平衡の流れとな る。そこでは速度が回転軸方向には変化しないという ティラー・プラウドマンの定理が成立する。

エクマン層（Fig. 1の k, l, k', l'）は, 回転軸に平行 でない壁近傍に形成される境界層で, 内部領域 (i, i') の速度分布を壁面粘着条件と整合させる働きをもつ。 一方, スチュワートソン層 $\left(\mathrm{m}, \mathrm{n}, \mathrm{n}^{\prime}\right)$ は, 回転軸に平 行な壁面近傍（mのうちコアの円柱壁面近傍部分）お よび方位角方向速度の勾配をもつ回転軸に平行なとこ ろ（mの残りの部分と $\left.\mathrm{n}, \mathrm{n}^{\prime}\right)$ に形成される境界層であ る。前者の壁面上のスチュワートソン層は，この層の 片側に位置する領域の速度分布を壁面粘着条件之整合 させる働きをもち、後者の自由スチュワートソン層 は，この層の両側の領域の速度分布を整合させる働き をもつ。

\section{2 エクマン層および内部領域流れ}

まず部分分級効率に影響を与えるエクマン層と内部 領域の流れ構造について説明する。Eqs. (15), (14) で表される定常・軸対称のエクマン層・内部領域流れ の理論解は, Eq. (15) の最高階微分の係数 $E$ が微小 であるので特異掑動法により以下のように導出でき る $^{9)}$ 。

内部領域 (Fig. 1 の i, i') の速度成分

$$
\begin{aligned}
u_{1}= & 0+\mathrm{O}(E) \\
v_{1}= & -4 C_{\mathrm{Q}} r^{-1}\left[\left(1+b_{\mathrm{L}}{ }^{2}\right)^{0.25}\right. \\
& \left.+\left(1+b_{\mathrm{U}}{ }^{2}\right)^{0.25}\right]^{-1}+\mathrm{O}\left(E^{0.5}\right)=\mathrm{O}\left(E^{0}\right) \\
w_{1}= & -C_{\mathrm{Q}} E^{0.5} r^{-1} \\
& \times\left(1+b_{\mathrm{L}}{ }^{2}\right)^{-0.75}\left(1+b_{\mathrm{U}}{ }^{2}\right)^{-0.75} \\
& \times\left\{b_{\mathrm{L}}{ }^{\prime} b_{\mathrm{L}}{ }^{\prime}\left(1+b_{\mathrm{U}}{ }^{2}\right)-b_{\mathrm{U}}{ }^{\prime} b_{\mathrm{U}}{ }^{\prime \prime}\left(1+b_{\mathrm{L}}{ }^{2}\right)\right\} \\
& \times\left[\left(1+b_{\mathrm{L}}{ }^{2}\right)^{0.25}+\left(1+b_{\mathrm{U}}{ }^{2}\right)^{0.25}\right]^{-2}+\mathrm{O}(E) \\
= & \mathrm{O}\left(E^{0.5}\right)
\end{aligned}
$$

エクマン層 $\left(\mathrm{k}, \mathrm{l}, \mathrm{k}^{\prime}, \mathrm{l}^{\prime}\right)$ の速度成分

$$
\begin{aligned}
u & =-\left(1+b^{\prime 2}\right)^{-0.5} v_{1} \exp (-\tau) \sin \tau=\mathrm{O}\left(E^{0}\right) \\
v & =v_{1}[1-\exp (-\tau) \cos \tau]=\mathrm{O}\left(E^{0}\right) \\
w & =-b^{\prime}\left(1+b^{\prime 2}\right)^{-0.5} v_{\mathrm{I}} \exp (-\tau) \sin \tau=\mathrm{O}\left(E^{0}\right) \\
G & =\left(1+b^{\prime 2}\right)^{-0.5}\left(b^{\prime} w+u\right) \\
& =-v_{1} \exp (-\tau) \sin \tau=\mathrm{O}\left(E^{0}\right)
\end{aligned}
$$

ここで， $b$ は軸対称の壁形状を表す $r$ の任意関数であ り, 添字 $\mathrm{L}, \mathrm{U}$ は各流れ場において $b$ の值がそれぞ れ小，大の壁 (下壁，上壁）近傍のエクマン層に関す る変数を表す。 $C_{\mathrm{Q}}$ は上，下壁間を流れる無次元流量 で, $\tau$ (次式) は後述のエクマン層厚さ相当の $(\nu /$ $\left.\Omega_{\mathrm{N}}\right)^{0.5}$ で無次元化された各壁に垂直な桩大座標であ る。

$$
\begin{aligned}
\tau= & \tau^{*} /\left(\nu / \Omega_{\mathrm{N}}\right)^{0.5} \\
= & ( \pm 1) E^{-0.5}(z-b)\left(1+b^{2}\right)^{-0.75} \\
& ( \pm 1=1(\text { 下壁 }),-1 \text { (上壁) })
\end{aligned}
$$




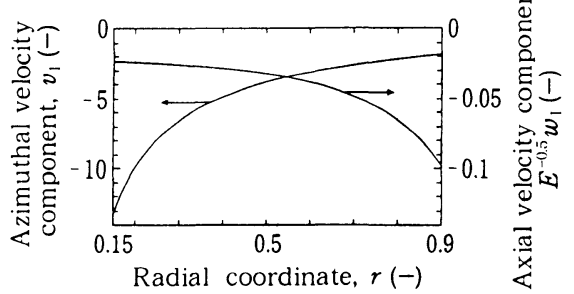

Fig. 9 Radial distributions of the azimuthal and axial velocity components, $v_{1}$ and $w_{1}$, in the interior region $\mathrm{i}$

Fig.9は, Fig. 2 (b) の実験装置の同心二重球面部 分の

$$
\begin{aligned}
& \text { 下壁 : } b_{\mathrm{L}}=\left\{1.21^{2}-r^{2}\right\}^{0.5}, \\
& \text { 上壁 : } b_{\mathrm{U}}=\left\{1.30^{2}-r^{2}\right\}^{0.5} \quad(0.15<r<1, z>0)
\end{aligned}
$$

の間の内部領域 $\mathrm{i}\left(C_{Q}=1\right)$ での速度分布を示す。方位 角方向速度 $v_{\mathrm{I}}$ は, 半径 $r$ の増大とともに回転系の速 度 $\left(v_{1}=0\right)$ に近つくく。これは, Eq. (16b)において, 下，上壁球面の性質上，傾き $b_{\mathrm{L}}{ }^{\prime}, b_{\mathrm{U}}{ }^{\prime}$ の絶対値が $r$ と ともに増大するからである。一方， $\mathrm{O}\left(E^{0.5}\right)$ の微小量 で，壁の傾きだけでなくその変化率 $b_{\mathrm{L}}{ }^{n}, b_{\mathrm{U}}{ }^{n}$ にも依 存する軸方向速度 $w_{\mathrm{I}}$ (Eq. (16c)) は, 絶対值が $r$ と ともに増大する負の值（軸方向下向き流れ）を示す。 なお半径方向速度 $u_{1}$ は， $u_{1}$ によるコリオリカが方位 角方向の压力勾配とつりあうので $\left(u_{1}=-r^{-1} \partial p_{1} /\right.$ $\partial \phi)$, 軸対称流である限り壁形状に無関係に零であ る。

Fig.10は，上述の同心二重球面近傍に生じるエクマ ン層での方位角方向速度 $v$, 接線方向速度 $G$ の壁の法 線 $(\tau)$ 方向分布を示す。 $v /\left(-v_{1}\right)$ および $G /\left(-v_{1}\right)$ の $\tau$ 分布形状は, 回転二円板 $\left(b_{\mathrm{L}}{ }^{\prime}=b_{\mathrm{U}}{ }^{\prime}=0\right)$ の場合と同じ であり，分布形状に壁形状（傾き $b^{\prime}$ ，曲率 $b^{\prime \prime}$ ）の影 響が陽に現れない。これは，Eqs. (17b)，(17d）か ら知られるように壁形状の影響が $v_{1}$ (Eq. $\left.(16 \mathrm{~b})\right)$ と $\tau$ (Eq. (18)）にすへてて含まれるからである。なお半径 および軸方向速度 $u, w$ の分布形状には $b$ が陽に現れ る。

Fig. 10 において, $v, G$ がともに $\tau \doteqdot \pi$ (有次元量 では $\left.\tau^{*} \fallingdotseq \pi\left(\nu / \Omega_{\mathrm{N}}\right)^{0.5}\right)$ で内部領域での各值（ $G_{1}$ は $\mathrm{O}\left(E^{0.5}\right)$ の微小量) に漸近することから，エクマン層 厚さ（有次元 $\delta^{*}$, 無次元 $\left.\delta\right)$ について次式が得られ る。

以下でさらにエクマン層流れを考察するため, 次式 で定義されるエクマン輸送量 $q$ ( 各エクマン層の $r$ 断 面を通過する流量で $Q$ による無次元量）を導入する。

$$
\begin{aligned}
q= & 0.25 \int_{0}^{\infty} 2 r u\left(1+b^{\prime 2}\right)^{0.75} \mathrm{~d} \tau \\
= & C_{\mathrm{Q}}\left(1+b^{\prime 2}\right)^{0.25}\left[\left(1+b_{\mathrm{L}}{ }^{2}\right)^{0.25}\right. \\
& \left.+\left(1+b_{\mathrm{U}}{ }^{2}\right)^{0.25}\right]^{-1}+\mathrm{O}\left(E^{0.5}\right)=\mathrm{O}\left(E^{0}\right) \\
\therefore & q_{\mathrm{L}}+q_{\mathrm{U}}=C_{\mathrm{Q}}, q_{\mathrm{L}}+q_{\mathrm{U}}=0
\end{aligned}
$$

このエクマン輸送量 $q$ と前述のエクマン層厚さ $\delta$, 内 部領域の軸方向速度 $w_{1}$ との間には, Eqs. (20), (16c) より，次式の関係が成立することが知られる。

$$
\begin{aligned}
& q_{\mathrm{L}} / q_{\mathrm{U}}=\left(1+b_{\mathrm{L}}{ }^{2}\right)^{0.25} /\left(1+b_{\mathrm{U}}{ }^{2}\right)^{0.25} \sim \delta_{\mathrm{L}} / \delta_{\mathrm{U}}(22 \mathrm{a}) \\
& \begin{aligned}
w_{\mathrm{I}} & =-2 E^{0.5} r^{-1} q_{\mathrm{L}}{ }^{\prime}=2 E^{0.5} r^{-1} q_{\mathrm{U}}{ }^{\prime} \\
& =-E^{0.5} r^{-1}\left(q_{\mathrm{L}}{ }^{\prime}-q_{\mathrm{U}}{ }^{\prime}\right)
\end{aligned}
\end{aligned}
$$

Fig. 11 は，下，上壁が任意形状の場合のエクマン層 $\mathrm{k} ， 1$, 内部領域 $\mathrm{i}$ について上記の関係を示す。 $\delta$ は Eq. (20) より $\Omega_{\mathrm{N}}^{0.5}$ に反比例する。ゆえにFig. 11に示 すような下壁の曲率が上壁よりも大きい場合には, $r$ において $\Omega_{\mathrm{NL}}<\Omega_{\mathrm{NU}}$ であるので $\delta_{\mathrm{L}}>\delta_{\mathrm{U}}$ となる。した がって， Eq. (22a)（ $\delta$ の大きい方が大きなエクマン 輸送量 $q$ を示す）より $q_{\mathrm{L}}>q_{\mathrm{U}}$ となる。そして上記の $r$ よりも大きな半径では，上壁のエクマン層厚さ $\delta_{\mathrm{U}}$ が $r$ でのその厚さよりも厚くなるが $\left(\Omega_{\mathrm{NU}}\right.$ の減少のた め), 下壁の $\delta_{\mathrm{L}}$ の方がさらに厚くなるので, $q_{\mathrm{U}}$ は $r$ 位置でのその值よりも減少し， $q_{\mathrm{L}}$ の方は增大する (Eq. (21b) の $q_{\mathrm{L}}{ }^{\prime}+q_{\mathrm{U}}{ }^{\prime}=0$ のゆえ)。なお，これらの エクマン輸送量の増減は, Eq. (22b) から知られるよ うに内部領域での下向きの軸方向流れ $w_{1}$ によっても 


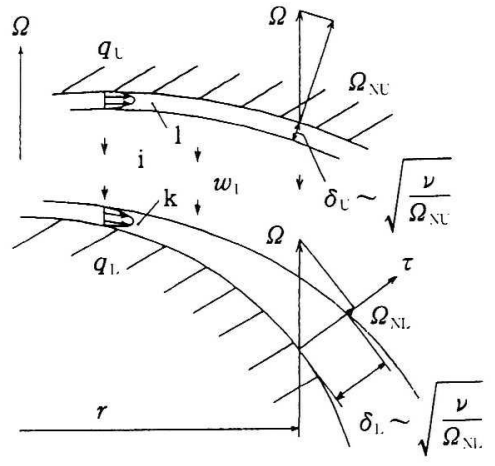

Fig. 11 Schematic of the relationship among the Ekman transport $q$, the thickness $\delta$ of the Ekman layer, and the interior axial velocity component $w_{1}$

たらされる。

\section{3 剛体回転領域生成のための条件}

剛体回転領域 j (Fig. 1) は, 粗粉産物の捕集域と して不可欠である。その生成条件は次のようである。 流れ場がFig. 1の j 部分に見られるように外側が閉じ た形状でありさえすれば（壁形状 $b_{\mathrm{L}}, b_{\mathrm{U}}$ の関数形に (無関係), $\mathrm{j}$ 内の $r$ が一定の円筒面を通過する流量 $C_{Q}$ は零であるので, Eqs. (16), (17) よりすべての速 度成分が零となり $\mathrm{j}$ は剛体回転領域となる。すなわ ち, 生成条件は流れ場を回転軸に向かって凹型形状に することである。

\section{4 スチュワートソン層の流れ構造}

部分分級効率に最も重要な役割を果たすのは, Fig. 1 中のエクマン層 $\mathrm{k}$ とスチュワートソン層 $\mathrm{m}$ の流れで ある。エクマン層についてはすでに述へたので,ここ ではスチュワートソン層の流れ構造の概略を述べる。

Fig. 12 は, 実験装置の容器形状に対して既報 ${ }^{10)}$ の数 値解析手法により得た軸対称の準剛体回転流の流線図 を示す。なお左の図は右の図の拡大眓であるが, 流れ 関数の值が異なる流線を示している。コアの円柱面お よびその延長線の近傍にスチュワートソン層が生じ, それは円柱面に沿った貫流領域とその外側の循環流 領域からなっている。スチュワートソン層は一般に $\mathrm{O}\left(E^{1 / 3}\right)$ および $\mathrm{O}\left(E^{1 / 4}\right)$ の厚さの $E^{1 / 3}$ 層と $E^{1 / 4}$ 層から なる複合層である。Fig. 12では $E$ の值に対応した $E^{1 / 3}$ および $E^{1 / 4}$ の厚さを記入している。これより $E^{1 / 3}$ 層が貫流領域, $E^{1 / 4}$ 層が循環流領域に対応する ことが分かる。

\section{5 安定な準剛体回転成層流の生成条件}

安定・軸対称の準剛体回転流の生成条件を実験的に 求めるため, 貫流に注入したウラニン色素 $\left(\mathrm{C}_{20} \mathrm{H}_{10}\right.$

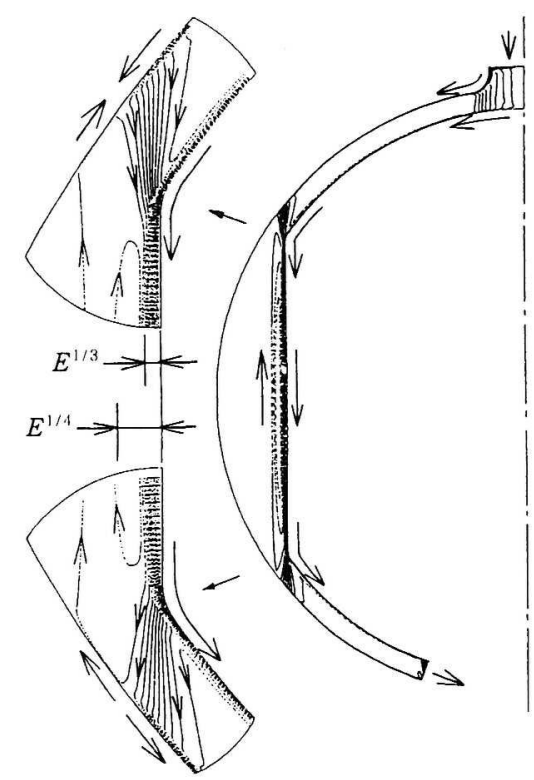

Fig. 12 Numerically simulated stream lines of the axisymmetric almost rigidly rotating flow for $E=5.0 \times 10^{-6}$ and $R_{\mathrm{S}}=1.22 \times 10^{-2}$

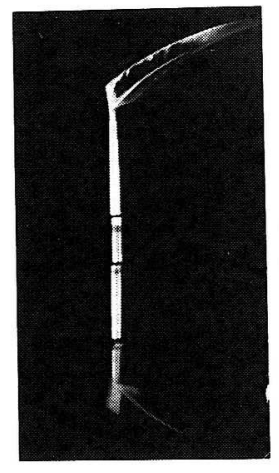

(a) Visualized streak lines

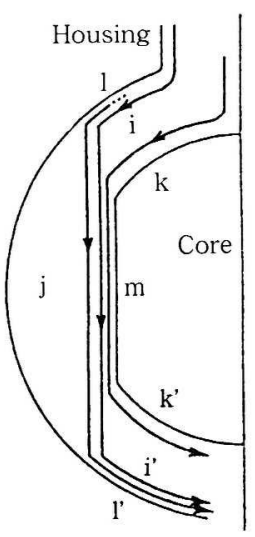

(b) Schematic of stream lines
Fig. 13 Stable axisymmetric regime of the almost rigidly rotating flow for $E=5.0 \times 10^{-6}$ and $R_{\mathrm{S}}=1.5 \times 10^{-2}$

$\left.\mathrm{O}_{5} \mathrm{Na}_{2}\right)$ にアルゴンレーザを照射して蛍光色素流脈を 観察した。Fig. 13（a）は原料粉体分散液の代わりに 水を流した場合の流脈写真であるが, 分散液の濃度が 希薄であるため分散液を流した場合との明確な相違は 認められなかった。観察により $0<R_{\mathrm{S}} \leqq 2.5 \times 10^{-2}$, $4.0 \times 10^{-6} \leqq E \leqq 8.0 \times 10^{-6}$ の流れ条件では, Fig. 13 (b)（流脈から求めた流線のスケッチ）に示すよう 
な安定・軸対称の準剛体回転流が生成されることが分 かった。

\section{6 流れ構造と分級性能との関係}

前述したように原料粉体分散液をコアの回転軸上に 導きエクマン層 $\mathrm{k}$ 内に供給することが必要である。な ぜならもしもすきま全体に供給すれば原料粉体分散液 がエクマン層1にも入り込み（Fig. 1, Fig. 12参 照), 八ウジング壁近傍に達する微粒子はスチュワー トソン層mにおいて剛体回転領域 $\mathrm{j} へ と$ 進むため, 粗 粉産物として捕集されてしまうので分級精度が悪化す るからである。

エクマン層 $\mathrm{k}$ に供給された粒子は, 壁の接線方向速 度 (Fig. 10の $G /\left(-v_{1}\right)$ )によりコア壁に沿って方位角 方向の強いせん断作用 $\left(v /\left(-v_{1}\right)\right.$ 参照) を受けて, 粒 子の軌道分離が生じる。また内部領域の軸方向速度 (Fig. 9 の $w_{1}$ ) が負なのでハウジングからコアに向か う流れ (Fig. 11参照) が存在するため, 微粒子がハウ ジング側のエクマン層1に運ばれるようなことは起こ り得ない。エクマン層 $\mathrm{k}$ からスチュワートソン層 $\mathrm{m} に$ 達した粒子は， $E^{1 / 3}$ 層あるいは $E^{1 / 4}$ 層（Fig. 12）に おいて軌道分離が促進され, 最終的に粗粒子は剛体回 転領域に閉じ込められ, 微粒子は流出口から排出され る。

以上のように, 本分級方式は, エクマン層内での強 いせん断流れとスチュワートソン層での高速回転流れ を相乗的に利用して粒子の軌道分離を効果的に促進す るとともに, 内部領域流れおよび剛体回転領域を利用 して高精度分級を達成するという特色をもっている。 分級試験で得られた分級の鋭さ, 分級径, 微粉収率 （3. 3節）に及ぼす $E$ と $R_{\mathrm{S}}$ の影響については，粒子に 作用する遠心力と流体抗力の比 (Eq. (3)) から分かる ように定性的には同じ影響を与える。しかし，実験結 果が示すように定量的に相違が見られるのは，Eq. （3）における粒径 $D_{\mathrm{P}}$ の差と入口における粒子のバラ ツキの状態によって, それぞれの粒子の軌道に差が生 じ，そのため $|\boldsymbol{v}-\boldsymbol{u}|$ が粒子ごとに相違してくる。し たがって時間的に積分された粒子軌道を考察しなけれ ば詳細は解明できない。現在, それについて研究して いる段階である。

\section{5. 結言}

高速回転二重容器内に微量の水を貫流させて生成し た安定な軸対称の準剛体回転流を分級に応用する新し い湿式遠心分級方式を提案する。このような準剛体回 転流では, 微小な貫流量下でいくら高速回転にしても 完全な軸対称成層流が保たれるので, 従来の方式では 得られない高性能の分級が可能である。また, 粒子に 作用する流体抗力に対する遠心力の比を任意に設定で きる特徴がある。したがって, 本方式は原理的にサブ ミクロン粒子に至る広範囲の微小粒径で高精度分級が 可能である。本論文では, 円柱・球形状の容器を用い たバッチ方式分級について考察し, 以下の結論を得 た。

（1）回転数が一定の場合貫流量が小さいほど, また貫 流量が一定の場合回転数が大きいほど, 分級径およ び微粉収率は小さく, 分級の鋭さは完全分級の值に 近づく。

（2）粗粉産物の捕集域である剛体回転領域を生成させ るための条件は, 流れ場の形状を回転軸に向かって 任意の凹型の片側が閉じた形状にすることである。

(3) 内部領域の軸方向流れは, 半径方向にエクマン輸 送量が減少する壁から増大する壁に向かう方向をと る。

（4）スチュワートソン層は, 回転コアの円柱面に沿っ た貫流領域とその外側の循環流領域からなる。

(5) $4.0 \times 10^{-6} \leqq E \leqq 8.0 \times 10^{-6}, 0<R_{\mathrm{S}} \leqq 2.5 \times 10^{-2}$ の範 囲のエクマン数 $E$, ロスビー数 $R_{\mathrm{S}}$ の流れ条件で は, 安定な軸対称の準剛体回転流が生成される。

（6）高精度の分級性能は，流れの構造の詳細を理解す ることによってもたらされるものである。すなわ ち, 回転コア壁近傍のエクマン層 $\mathrm{k}$ への原料粉体分 散液の供給, エクマン層内の強いせん断流れによる 粒子の分散, ハウジングからコアに向かう内部領域 流れ i により微粒子をコア壁近傍にとどめようとす

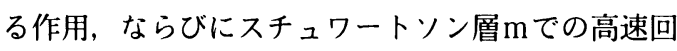
転流れの相乗効果による粒子軌道分離の促進による ものであると考えられる。

本研究は, 文部省科学研究費補助金・試験研究 B2 （H3〜 5年度 03555037）の援助を受けた。ここに付 記し謝意を表す。

\section{Nomenclature}

$A \quad$ : constants (Eq. (8)) 


\begin{abstract}
an axisymmetric wall configuration (-)
$C$ : mass concentration of suspension (-)

$C_{\omega}$ : flow rate, non-dimensionalized by $Q$, of the flow between lower and upper walls (-)

$D_{1}$, : diameter of a spherical particle (m)

$D_{p}$ : particle diameter for $\Delta \eta=N(\%)\left(D_{1 ; 0)}:\right.$ cut size $)$
\end{abstract}

E : Ekman number (Eq. (4))

$(\mathrm{m})$

$(-)$

$f\left(D_{1}\right)$ : frequency distribution (mass base, Eqs. (9), (12))

$\left(\mathrm{m}^{-1}\right)$

$\boldsymbol{F}_{\mathrm{c}} \quad$ : centrifugal force acting on the particle (Eq. (1))

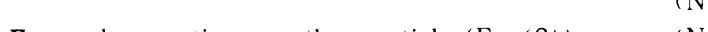

$\boldsymbol{F}_{\mathrm{d}} \quad$ : drag acting on the particle (Eq. (2)) (N)

$G \quad$ : dimensionless velocity component tangential to the wall (Eq. (17d))

$(-)$

$\boldsymbol{i}, \boldsymbol{k}$ : unit vectors in the radial and axial directions

$k_{0}:$ feed-suspension ratio, $Q_{1} / Q \quad(-)$

$n$ : rotation rate of the rotating container, $30 \Omega / \pi$

$(\mathrm{rpm})$

$p \quad$ : pressure reduced by a centrifugal force, nondimensionalized by $\rho_{\mathrm{r}} \Omega a U_{\mathrm{i}} \quad(-)$

$Q \quad$ : through-flow rate $\left(\mathrm{m}^{3} / \mathrm{s}\right)$

$Q_{1}$ : flow rate of the feed suspension $\left(\mathrm{m}^{3} / \mathrm{s}\right)$

$q \quad:$ Ekman transport at $r$ on each wall, nondimensionalized by $Q$ (Eq. (21a)) (-)

$R\left(D_{1}\right) \quad$ : oversize distribution (mass base, Eqs. (8), (11))

$R_{\mathrm{S}} \quad$ : Rossby number (Eq. (4))

$(-)$

$(-)$

$\left(r^{*}, \phi, z^{*}\right)$ : rotating cylindrical coordinate system (radial, azimuthal, and axial coordinates), $(a r, \phi, a z)$

$S \quad$ : sharpness index, $D_{1225} / D_{175}$

$\boldsymbol{u}^{*}$ : flow velocity vector, $U_{1:} \boldsymbol{u}$ $(u, v, w) \quad$ : dimensionless velocity components in the rotating cylindrical coordinate system (-)

$U_{1:}:$ characteristic velocity, $Q /\left\{4 \pi a(\nu / \Omega)^{0.5}\right\} \quad(\mathrm{m} / \mathrm{s})$

$\boldsymbol{v}^{*}:$ particle velocity vector, $U_{\mathrm{f}} \boldsymbol{v} \quad(\mathrm{m} / \mathrm{s})$

$x: \log _{10} D_{\mathrm{p}}$, (Eq. (8)) (-)

$y \quad: A_{1} x+A_{2} \sin \left(A_{3} x\right)+A_{1}$ (Eq. (8))

$\gamma: \rho_{1} / \rho_{\mathrm{r}}$

$\eta_{1}:$ : yield of fine product (Eq. (7)) (-)

$\Delta \eta\left(D_{\mathrm{l}}\right) \quad$ : partial fractional efficiency of the fine product (Eq. (10)) (-)

$\delta \quad$ : dimensionless Ekman-layer thickness at $r, \delta^{*} / a$ (Eq. (20)) (-)

$\mu \quad$ : viscosity of fluid $\quad(\mathrm{Pa} \cdot \mathrm{s})$

$\nu \quad:$ kinematic viscosity of fluid, $\mu / \rho_{\mathrm{r}} \quad\left(\mathrm{m}^{2} / \mathrm{s}\right)$

$\rho_{\mathrm{r}}, \rho_{\mathrm{l}}$, : densities of fluid and particle respectively

$\left(\mathrm{kg} / \mathrm{m}^{3}\right)$

$\tau$ : dimensionless stretched coordinate normal to the wall in each Ekman layer (Eq. (18)) (-)

$\Omega \quad$ : angular velocity of the rotating container

$(\mathrm{rad} / \mathrm{s})$

$\Omega$ 、 : angular velocity component normal to the wall at $r,\left(1+b^{\prime 2}\right)^{-10.5} \Omega \quad(\mathrm{rad} / \mathrm{s})$

Subscripts

C, F : concerning the coarse and fine products respectively

I : concerning interior regions

$\mathrm{L}, \mathrm{U}$ : concerning the lower and upper walls with small and large axial coordinates respectively

$\mathrm{O}$ : concerning the feed suspension

W : concerning the water supplied

Superscripts

- derivatives with respect to $r$

* : variables with dimension corresponding to the dimensionless ones

\section{References}

1) Tanaka, Z., T. Inoue, J. Hidaka and S. Miwa : "Basic Lectures of Powder Technology 2, Chapter 2 Classification", J. Soc. Powder Technol., Japan, 25, 221-230 (1988)

2) Tanaka, Z., T. Miya and T. Takahasi : "Wet Size Classification for Fine Particles in Centrifuges", J. Soc. Powder Technol., Japan, 29, 750-754 (1992)

3 ) Isshiki, Y., K. Fukui, H. Yoshida and A. Kobayashi : "The Control of Particle Size Separation by the Use of a Hydrocyclone", J. Soc. Powder Technol., Japan, 34, 690-696 (1997)

4 ) Okuda, S. : "On Accurate Classification of Fine Particles”, J. Soc. Powder Technol., Japan, 26, 451-458 (1989)

5 ) Harada, I. and N. Ozaki : “A Numerical Study of Source-Sink Flows in a Rotating Cylinder", J. Phy. Soc. Japan., 45, 1400-1409 (1978)
6 ) Nakabayashi, K. et al. : Basic Study on Fine Particles in Almost Rigidly Rotating Flow (4th Report, Experimental Consideration of Classification Efficiency)", Trans. Japan Soc. Mech. Eng., 594, 586-592 (1996)

7 ) Kimura R. : "Introduction to Geophysical Fluid Dynamics", pp. 27-45, Tokyodo Press (1987)

8 ) Greenspan, H. P. : "The Theory of Rotating Fluids", pp. 28-118, Cambridge University Press (1968)

9 ) Nakabayashi, K and Y. Tsuchida: "Basic Study on Fine Particles in Almost Rigidly Rotating Flow (1st Report, Theoretical Consideration of Flow)", Trans. Japan Soc. Mech. Eng., 591, 3989-3995 (1995)

10) Morinishi, Y. et al. : "Computational Method for Almost Rigidly Rotating Flow", Trans. Japan Soc. Mech. Eng., 572, 1234-1241 (1994) 